Лидия Енина

ORCID: 0000-0003-2073-9948

Уральский федеральный университет им. первого Президента России Б.Н. Ельцина

Екатеринбург, Россия

\title{
АВТОБИОГРАФИЯ ДЛЯ МУЗЕЯ: ДИСКУРСИВНЫЕ ПРАКТИКИ ТОЖДЕСТВЕННОСТИ И САМОСТИ НАИВНОГО АВТОРА ${ }^{1}$
}

\author{
https://doi.org/10.34739/clit.2020.14.14
}

\section{MUSEUM AUTOBIOGRAPHY: DISCURSIVE PRACTICES OF THE IDENTITY AND SELF OF THE NAIVE AUTHOR}

The article is devoted to the study of discursive identity based on autobiographical texts written by Uralmashzavod employees in the 1970s. In her methodology the author draws on Michael Foucault's theory of discourse and Paul Ricoeur's idea of the bilateral nature of narrative identity. In an autobiographical discourse, identity practices construct the normative subjective position of official Soviet discourse. The practices of the self are considered in the aspect of confession and frankness. It is concluded that the subjective position in the discourse is simultaneously supported by the practices of identity, and shaken by the practices of the self.

Keywords: identity, autobiographical text, subjective position, discursive practices

\section{«Фонд первостроителей Уралмаша»: подход к исследованию}

(Авто)биографические тексты незамечательных, обыкновенных, так называемых «простых людей» долгое время исключались из поля зрения исследователей по причине их несоответствия литературному языку, эстетическим, а порой

\footnotetext{
1 Исследование выполнено при финансовой поддержке РФФИ, проект № 19-012о0553А «Первостроители как перформативный проект: конструирование дискурсивной идентичности уральских рабочих в текстах 1930-х и 1970-Х».
} 
и этическим нормам. Однако с обращением к проблеме субъектности, к ценности осмысления любой жизненной истории, а не только «жизни замечательных людей» наивное письмо стало востребовано филологами, историками, культурологами. Наше внимание к наивным текстам обусловлено не как к источнику историкоэтнографических сведений или философско-символических смыслов, а как свидетельству дискурсивного порядка, в котором содержатся сведения о поддерживаемых/отрицаемых социальных отношениях, о ценностных предпочтениях, нормах/антинормах поведения в семье и публичном пространстве ${ }^{2}$. Цель этой статьи показать, какие смыслы становятся маркерами исповедальности в воспоминаниях «простого человека».

Материалом для нашего анализа послужили не исследовавшиеся ранее автобиографические тексты работников машиностроительного завода «Уралмаш» - одного из флагманов советской индустриализации. Тексты написаны людыми, далекими от литературной деятельности и различающимися происхождением, образованием, достигнутым социальным статусом. Все эти тексты были собраны Музеем истории Уралмашзавода в период с 1967 года по 1985 год и хранятся в нем под названием «Фонд первостроителей Уралмаша». Нужно сказать, что написание и сбор этих воспоминаний были инициированы со стороны заводского парткома и профкома, которые преследовали прагматическую цель - выпустить книгу об истории Уралмаша, как бы продолжив проект «Истории фабрик и заводов», начатый А.М. Горьким в 1930-ые годы. Книга так и не была подготовлена и издана, а тексты остались в музее. Сегодня этот Фонд служит нам источником сведений о том, какой дискурсивный порядок воспроизводили «простые люди», когда писали автобиографию для музея.

Мы предлагаем дискурсивный подход к воспоминаниям. Суть нашего подхода состоит в том, что изучению подвергается самостоятельный дискурсивный феномен - совокупность текстов воспоминаний заводчан. В связи с разносторонним понятийным

\footnotetext{
${ }^{2}$ См. также: Голубев А., Ушакин С., Экс-позиция письма: о правилах чтения чужой переписки, [в:] XX век: Писъма войны, ред. С. Ушакин, А. Голубев, Москва 2016, с. 8-21; Козлова Н., Советские люди. Сцены из истории, Москва 2005; Лотман Ю., Литературная биография в историко-культурном контексте (К типологическому соотношению текста и личности автора), [в:] Ю. Лотман. Избранные статьи в трех томах. Том 1. Статьи по семиотике и типологии культуры, Таллинн 1992, с.365-376; Савкина И., Идентичность и модели женственности в дневнике «приживалки» (Е. Попова «Из московскойжизни сороковых годов»), [в:] Гендер: язык, культура, коммуникация. Доклады Второй международной конференции, Москва 2002, с. 274-280 и др.
} 
наполнением термина «дискурс» укажем, что мы опираемся на концепцию М. Фуко ${ }^{3}$. Хочется подчеркнуть, что исследование выполняется в русле отказа от фактологического или биографического прочтения этих документов: мы не выявляем достоверность сведений и не обращаемся к другим документам для установления жизненной траектории авторов.

Рассматриваемый дискурс является закрытым и тематически объединенным: все тексты посвящены воспоминаниям о строительстве завода в 1930-ые и дальнейшей работе завода/на заводе в советское время. В этом дискурсе мы выявляем дискурсивные практики - общие правила создания нарратива о себе и о строительстве Уралмаша. Таким образом, биографический подход к воспоминаниям заменен на анализ дискурсивных практик по конструированию субъектной позиции дискурса. Субъектная позиция понимается нами как нормативная позиция дискурса, с точки зрения которой ведется повествование и расставляются оценки событиям и персонажам. Для нас терминологически «субъектная позиция» и «автор» не вступают в синонимические отношения. Автор - это биографически конкретная личность, которая, когда пишет текст, следует определенным правилам создания текста, а субъектная позиция дискурса - это «дискурсивная версия» автора, она всегда шире или уже, «прямее» или «кривее» реального человека, хотя она напрямую связана с той идентичностью, которую сознательно или случайно конструирует автор текста. В нашем случае каждый текст дискурса представляет собой нарратив, посредством которого организуется история завода и собственной трудовой жизни автора. «Повествование созидает идентичность..., которую мы можем назвать... нарративной идентичностью, строя идентичность рассказываемой истории»4.

Мы воспользуемся концепцией Поля Рикера о двух сторонах идентичности в нарративе5. Он предложил выделять в идентичности индивида два аспекта идентификации - тождественность и самость. Тождественность для субъекта соотносится с семантикой «тот же самый», то есть похожий, сходный с кем-то. А самость обеспечивает семантику «отличие из ряда похожих», это делает субъекта самим собой, оставляет ему его непохожесть на других. В процессе написания истории трудовой жизни автор обращается то к смыслам тождественности, то к смыслам самости.

\footnotetext{
3 М. Фуко, Порядок дискурса, [в:] М.Фуко, Воля к истине: по ту сторону знания, власти и сексуальности, Москва 1996, с. 47-97.

4 П. Рикер, Я-сам как другой, Москва 2008, с. 180.

5 Ibidem.
} 
Для анализа наших автобиографических нарративов мы можем разграничить дискурсивные практики, конструирующие субъектную позицию, на те, что реализуют смыслы тождественности «я, как и все», и на те, что реализуют смыслы самости «я, в отличие om всех». Дискурсивные практики реализуются нелинейно, их обнаружение связано с поиском актуальных смыслов в нарративе.

Прежде чем мы перейдем собственно к анализу дискурсивных практик, необходимо сказать, что мы сохраняем в цитируемых текстах авторскую орфографию, пунктуацию и стилистику. Письменные тексты «простого человека» могут вызвать комический эффект у искушенного просвещенного читателя, а для нас анормативность письма есть дополнительное свидетельство неполного подчинения нормативной субъектной позиции. Мы придерживаемся мысли, которую точно сформулировала Ирина Сандомирская:

язык не является нейтральным средством для описания объективной действительности, и его нельзя подправить, не отредактировав при этом его реальности. Овладение функцией субъектности - правами легитимного говорения от первого лица приобретается в результате подчинения символическому порядку6.

Кроме этого, в буквальном сохранении авторского текста мы видим проявление уважения к конкретным людям, невольно ставшими нашими информантами. После цитирования авторского текста мы указываем фамилию с инициалами, а также шифр архивного фонда музея.

\section{Практики тождественности на службе нормативной субъектной позиции}

При первом прочтении текстов складывается впечатление об одинаковости, похожести, неяркости воспоминаний. Это происходит отчасти потому, что описывается одно и то же заводское пространство, хорошо знакомое каждому работнику: кузнечно-прессовый цех, механический цех, сталеплавильный цех, ремонтно-строительный цех, газогенераторная станция и пр. Дотошно перечисляются заводские станки и печи - мартеновские, сушительные, нагревательные, термические и пр. Часто в подробностях излагается производственный процесс и профессиональные обязанности:

${ }^{6}$ И. Сандомирская, «Наивное письмо» пятнадцать лет спустя, или На смерть соавтора, http:// https://magazines.gorky.media/nz/2012/2/naivnoe-pismo-pyatnadczatlet-spustya-ili-na-smert-soavtora.html, [дата доступа: 30.11.2019]. 
Конструкторский отдел занимался эскизировкой деталей всего парка оборудования, прежде чем эксплуатировать оборудование в момент его монтажа мы эскизировали детали, комплект составлялся инженером по оборудованию согласно его дефектной ведомости, кроме эскизов составлялась спецификация ш/подшипников, приводных цепей и ремней, а также комплектующих изделий / пусковая аппаратура [Смертина-Бергман Н.В. Ш24. П.2. Папка №14. Л.3].

Такие дискурсивные практики территориальной и профессиональной идентификации авторов передают прежде всего смыслы тождественности, $я$, как и все, в нашей профессии и на нашем заводе.

Субъектная позиция в рассматриваемом дискурсе обязательно требует правильные идеологические смыслы о руководящей роли партии, о партийной или комсомольской принадлежности авторов, их соратников и руководителей. Фрагменты воспоминаний, посвященные конкретным людям, тоже окрашиваются идеологически одобряемыми характеристиками: исполнительный, ответственный, политически грамотный, активный в общественнъх делах и пр. К исповедальности, откровенности такие смыслы отнести затруднительно. Более того, даже при рассказе о собственной жизни нередко подчеркивается, что жизнь прожита, как у всех. Ярким примером дискурсивного подавления практик индивидуализации служит речевой оборот как все, неоднократно повторяющийся в завершении текста Н.С. Рожиной:

Ну о себе неудобно писать. Никаких я подвигов не сделала не чем не награждалась, работала в бригаде как и все всю войну. Но после дня победы увольнялась из-за ребенка и 6 м-цев не работала, прерван стаж. Комсомолкой была как и все. На общественных работах была много и секретарем комс.организ. где 150 чел было не освоб. Кроме это не освобожд. воспитатель в общежитии по Кировгр. д.42, Индустрии 16. Жили эвакуированные дети. Вскоре муж умер, с 27 лет вдова, воспитала 2-х дочерей, одна окончила институт, другая техникум, как и все. По немногу но на пользу было все сделано [Рожина Н.С. Ш24. П 2. Папка № 14. Л.7].

Обнаруживающееся стремление авторов нарративов к растворению в коллективной идентичности вполне согласуется с выводом социолога Бориса Дубина, что советский человек в принципе неавтобиографический:

Советский человек - человек массовый и притом, как уже упоминалось, атомарный, в любом случае он - не самостоятельный и не индивидуальный. Но потому он, строго говоря, и не развивается, 
он не автобиографический и не автобиографируемый, если, конечно, не иметь в виду стандартизированную трудовую автобиографию, «учетный листок» для отдела кадров на производстве и прочих государственных нужд»7.

Однако этот вывод нельзя распространить на весь наш дискурс, в котором наряду с практиками тождественности находится место практикам самости, индивидуализации - практикам, с помощью которых автор выделяет, вырывает себя из своего окружения. На формальном уровне практики индивидуализации присутствуют в смене лингвистических маркеров, и на первое место в нарративе выходит местоимение «я» и глагольные формы единственного числа.

\section{Фокус исповедальности в практиках самости}

Одни из важных смыслов самости, носящих исповедальный характер, - смыслы о проявленной профессиональной смелости. Смелость, о которой пишут работники Уралмаша, вовсе не меняет исторический ход событий, не несет высокого патриотического смысла, она просто помнится как знак неподчинения. Нарративные фрагменты, в которых автор рассказывает, как пошел наперекор решению начальства, не подчинился вышестоящему или указал на его ошибки, - это частные эпизоды, но имеющие высокую индивидуальную значимость в контексте дискурсивно прожитой коллективной жизни. Приведем пример. И.А.Калинин вспоминает, как его командировали в г. Орск и он на заседании узкого партийно-хозяйственного актива выступил с критическим докладом о положении дел в Южноуральском машиностроительном заводе. В своем тексте он на нескольких страницах подробно пересказывает свое выступление и сделанные им конкретные замечания: отсутствие необходимых станков или их неправильное использование, неэффективная организация производства, большое количество бракованных деталей и т.д.

Мое выступление задело многих работников завода. Многие выступали вторично; одне оправдывались, другие выступали с критикой моих предложений. Особенно руководство завода не поддерживало моего предложения по реорганизации и разделению цехов, хотя убедительных доводов и не могли выдвинуть.

Б. Дубин, $O$ невозможности личного в советской культуре (проблемы автобиографирования), [в:] Б. Дубин, Классика после и рядом: социологические очерки о литературе и культуре, Москва 2010, с. 201. 
Заключительные выступления начальника Главка т. Новаковского и Министра т. Казакова Н.С. меня полностью реабилитировали. ... На другой день, придя на завод, мы снова разошлись по цехам. И вот, где-то часов 10 утра по селектору слышу голос диспетчера: «Внимание! Внимание! Представитель Уралмашзавода т.Калинин срочно зайдите в кабинет директора завода! Вас вызывает Министр!» Услышав такие слова я даже растерялся, думаю, может быть вчера что-то лишнее наговорил. Понурив голову направился в дирекцию завода [Калинин И.А. Ш24. П1. Папка №8. Л.8].

Исповедальность проявляется не только в фактической стороне поступка, но и в том, что автор говорит о своих и чужих эмоциях, признается в испуге за сказанное. Судя по фрагменту, для И.А. Калинина все закончилось благополучно, его замечания приняли и предложили ему должность заместителя начальника цеха на этом заводе. Вообще, поступки профессиональной смелости, описанные в воспоминаниях, заканчиваются всегда успешно, выгодно для автора. Для субъектной позиции нашего автобиографического дискурса практики самости, как и практики тождественности, связаны тональностью победного нарратива, который не пропускает негативных воспоминаний, личных обид, тягостного прошлого.

Другие смыслы самости, которые мы относим к исповедальным, - это воспоминания анекдотичных историй. Персонажами таких историй выступает ближнее окружение рассказчика, и смеховой эффект направлен, как правило, на самого рассказчика. Смех вносит индивидуализацию в практики коллективной тождественности, расшатывает устойчивую идеологическую конструкцию коллективного советского субъекта. В следующем фрагменте речь идет об инженере, направленном в Германию перенимать опыт. Он признается в своей неискушенности, наивности при выборе одежды, чтобы ехать за границу:

1931 год я был командирован в Германию ...Прежде всего нужно было иметь соответствующий верхний костюм для выезда за пределы страны. Я получил для этой цели разрешение приобрести все необходимое в московском магазине «Торгсин». Попытка подобрать костюм в этом магазине не увенчалась успехом. Время для заказа небыло, тогда я остановился на великолепном комплекте верхней одежды сшитой из кожи (куртка, брюки и фуражка), вероятно образца, который носили в 1920 г. В этой верхней одежде я выехал осенью 1931 года в Германию. ... На вокзале меня встретил сотрудник постпредства и сразу же заявил, что подобную одежду в Берлине не принято носить. Это было правильное замечание, так 
как через незначительный срок своего пребывания в Берлине я обратил внимание, что на меня смотрят с удивлением и иногда просто не садились рядом на скамейку в трамвае. Пришлось обратиться к руководству Торгпредства о предоставлении мне очередного аванса для приобретения соответствующей верхней одежды. В течении одного вечера при помощи товарищей по работе я полностью переоделся, как говорят «с ног до головы» [Ивановский В.А. Ш24. П.1. Папка № 7. Л.9].

Хотя в этой «истории с улыбкой» заметна роль товарищей по работе, рассказчик смотрит на себя глазами берлинцев, которые для него Другие, но не враги. Это тоже практики самости, раскалывающие нормативную субъектную позицию советского официального дискурса.

\section{Выводы}

Подводя итог, скажем, что в автобиографическом дискурсе «Фонда первостроителей Уралмаша» активно воспроизводится нормативная субъектная позиция официального советского дискурса с обязательными практиками тождественности в идеологической, профессиональной и территориальной идентификации. Но в то же время в дискурсе реализуются практики самости, идущие вразрез с коллективной тождественностью. Маркерами исповедальности выступает фиксация личных эмоциональных переживаний недовольства, удивления, страха, а также смыслы профессиональной смелости и самоиронии. Автобиографии для музея, зафиксировав неоднозначный дискурсивный опыт, позволяют услышать голоса тех, кого принято считать «простыми людьми», и включить их в историю культуры.

\section{Литература}

Голубев А., Ушакин С., Экс-позиция письма: о правилах чтения чужой переписки, [в:] XX век: Письма войны, ред. С. Ушакин, А. Голубев, Москва 2016, с. 8-21.

Дубин Б., О невозможности личного в советской культуре (проблемы автобиографирования), [в:] Б. Дубин, Классика после и рядом: социологические очерки о литературе и культуре, Москва 2010, c. $197-207$.

Козлова Н., Советские люди. Сцены из истории, Москва 2005. 
Лотман Ю., Литературная биография в историко-культурном контексте (K типологическому соотношению текста и личности автора) [в:] Ю. Лотман. Избранные статьи в трех томах. Том 1. Статьи по семиотике и типологии культуры, Таллинн 1992, с. 365-376.

Рикер П., Я-сам как другой, Москва 2008.

Савкина И., Идентичность и модели женственности в дневнике «приживалки» (Е. Попова «Из московской жизни сороковьх годов»), [в:] Гендер: язык, культура, коммуникация. Доклады Второй международной конференции, Москва 2002, с. 274-280.

Сандомирская И., «Наивное письмо» пятнадцать лет спустя, или На смерть соавтора, http:// https://magazines.gorky.media/nz/2012/ 2/naivnoe-pismo-pyatnadczat-let-spustya-ili-na-smert-soavtora.html.

Фуко М., Порядок дискурса, [в:] М.Фуко, Воля к истине: по ту сторону знания, власти и сексуальности, Москва 1996, с. 47-97.

\section{References}

Golubev A., Ushakin S., Eks-pozitsiya pis'ma: o pravilakh chteniya chuzhoy perepiski, [v:] XX vek: Pis'ma vojny, red. S. Ušakin, A. Golubev, Moskva 2016, s. 8-21.

Dubin B., O nevozmožnosti ličnogo $v$ sovetskoj kul'ture (problemy avtobiografirovaniâ), [v:] B. Dubin, Klassika posle i râdom: sociologičeskie očerki o literature i kul'ture, Moskva 2010, s. 197-207.

Kozlova N., Sovetskie lûdi. Sceny iz istorii, Moskva 2005.

Lotman Û., Literaturnaâ biografiâ $v$ istoriko-kul'turnom kontekste (K tipologičeskomu sootnošeniû teksta $i$ ličnosti avtora), [v:] Û. Lotman. Izbrannye stat'i v treh tomah. Tom 1. Stat'i po semiotike i tipologii kul'tury, Tallinn 1992, s. 365-376.

Riker P., Â-sam kak drugoj, Moskva 2008.

Savkina I., Identičnost' $i$ modeli ženstvennosti $v$ dnevnike "priživalki» (E. Popova «Iz moskovskoj žizni sorokovyh godov»), [v:] Gender: âzyk, kul'tura, kommunikaciâ. Doklady Vtoroj meždunarodnoj konferencii, Moskva 2002, s. 274-280.

Sandomirskaâ I., "Naivnoe pis'mo» pâtnadcat' let spustâ, ili na smert' soavtora, http://https://magazines.gorky.media/nz/2012/2/ naivnoe-pismo-pyatnadczat-let-spustya-ili-na-smert-soavtora.html.

Fuko M., Porâdok diskursa, [v:] M.Fuko, Volâ k istine: po tu storonu znaniâ, vlasti $i$ seksual'nosti, Moskva 1996, s. 47-97. 